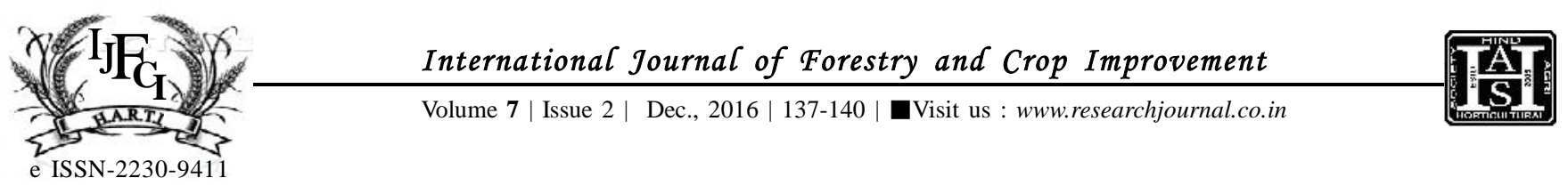

\title{
Studies on consumptive use, water use efficiency and moisture extraction pattern by Indian Mustard as influenced by limited irrigation and nitrogen levels
}

\author{
R.K. SAUD, B.P. SingHAND R.K. PANNU
}

\begin{abstract}
Field experiments were conducted at Hisar during Rabi season of 1999-2000 and 2000-2001 to study the effect of limited irrigation and nitrogen levels on consumptive use, water use efficiency and moisture extraction pattern by Indian mustard varieties. Total consumptive use (CU) of water and water use efficiency (WUE) was higher in the variety Laxmi than RH-9304. However, Laxmi and RH-9304 showed a tendency to extract more or less same amount of moisture from different soil depths. Irrigation levels resulted in marked increase in the total consumptive use of water over no post sowing irrigation. The highest consumptive use of 168.72 and $160.56 \mathrm{~mm}$ was found in one irrigation applied at flowering stage during 1999-2000 and 2000-2001, respectively. The WUE decreased with the application of irrigation water over no irrigation. Irrigation levels markedly influenced the soil moisture extraction patterns. The irrigated crop extracted more moisture from upper (0-30 CM) of soil lalyens as compared to unirrigated crop. The highest CU of water was observed at $120 \mathrm{~kg} \mathrm{Nha}^{-1}$. However, higher WUE was recorded at $100 \mathrm{~kg} \mathrm{Nha}^{-1}$.

KEY WORDS : Consumptive use, Water use efficiency, Moisture extraction pattern, Indian mustard, Limited irrigation, Nitrogen levels

How TO CITE THIS ARTICLE : Saud, R.K., Singh, B.P. and Pannu, R.K. (2016). Studies on consumptive use, water use efficiency and moisture extraction pattern by Indian Mustard as influenced by limited irrigation and nitrogen levels. Internat. J. Forestry \& Crop Improv., 7 (2) : 137-140, DOI: 10.15740/HAS/IJFCI/7.2/137-140.
\end{abstract}

Article Chronical : Received : 30.08.2016; Revised : 01.11.2016; Accepted : 15.11.2016 